\title{
AN EXTENDED TODIM METHOD FOR PROJECT MANAGER'S COMPETENCY EVALUATION
}

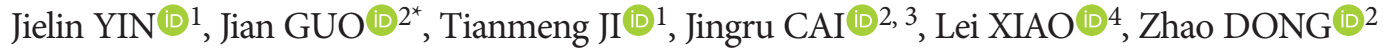 \\ ${ }^{1}$ School of Economics and Management, Beijing Information Science \& Technology University, Beijing, China \\ ${ }^{2}$ School of Management Science and Engineering, Central University of Finance and Economics, Beijing, China \\ ${ }^{3}$ Taiyuan Central Sub-branch, People's Bank of China, Taiyuan, China \\ ${ }^{4}$ School of Economics and Management, University of Electronic Science and Technology of China, \\ Chengdu, China
}

Received 11 January 2019; accepted 15 April 2019

\begin{abstract}
The project managers' high efficiency and leadership ability is very important for the success of the whole project. Evaluating the competency of project manager accurately and selecting the suitable project manager from alternatives is a very core research issue that should be paid high attention to in the field of project management. When evaluating the competency of project manager, multiple criteria with interactive relationship should be considered, and the decision makers may have bounded rational behavior which may have a great impact on the result of evaluation, whereas the decision makes' psychological behavior is rarely taken into account in the existing studies on the evaluation of project managers' competency. TODIM (an acronym in Portuguese of interactive and multi-criteria decision making) is a multi-criteria decision making method considering the decision makers' behavior. In this paper, an extended TODIM method which combines $\lambda$-fuzzy measure with Choquet integral considering incomplete criteria information and decision makers' bounded rational behaviors are presented to evaluate the competency of project manager. Furthermore, a numerical example is presented to illustrate the method proposed. We hope that this method can provide some valuable references for the evaluation of project manager's competency.
\end{abstract}

Keywords: $\lambda$-fuzzy measure, Choquet integral, TODIM, project manager's competency, bounded rational behavior.

\section{Introduction}

The investment in infrastructure project is a key prerequisite for economic development. The construction of infrastructure project, such as roads, railway, subway, electricity and water resources supply, sewage and garbage treatment, ecological and environmental protection, have great impact on the lives of all citizens. The construction and upgrading of infrastructure project is an indispensable part of sustainable economic growth and is the foundation of social progress. It is preliminarily estimated that the expenditure of the global infrastructure investment has gradually increased from 1.8 trillion dollars in 2007 to 2.3 trillion dollars in 2015, with an average annual growth rate of $2.9 \%$. As an important part of world GDP, the expenditure of the global infrastructure investment has remained at around 3\% in the past 10 years. In most cases, infrastructure investment accounted for about $12 \%$ of total global investment. Therefore, the construction and operation of infrastructure projects is a key component for the rapid development of the global economy and has a considerable effect on the lives of the populace (Hanna, Ibrahim, Lotfallah, Iskandar, \& Russell, 2016). However, the infrastructure project faces challenges of inefficiency and low productivity, which often result in the failure to deliver construction projects on time and on budget (Hanna, 2010). Project managers are responsible for the overall success of a construction project, which includes meeting goals related to cost, schedule, quality, and safety (Russell, Jaselski, \& Lawrence, 1997). Since success of the infrastructure projects depends heavily on project managers, the competency of project managers is closely related to the success or failure of infrastructure projects. Therefore, how to evaluate the competency of project manager accurately has become an important and valuable research topic for scholars and practitioners in the field of project management.

*Corresponding author. E-mail: txmguojian2002@126.com 
Recently many researchers have paid high focus on the evaluation of the project managers' competency. However, the behavior of the decision makers and the interactive relation of multiple criteria are rarely considered in the existing studies. Just a few studies put the focus of research subject on competency of project manager. Zavadskas, Turskis, Tamosaitiene, and Marina (2008) made a literature review and proposed a series of criteria for the evaluation of construction managers' competency. Maaleki and Cyrus (2017) attempted to use an analytic network process (ANP) approach to evaluate the competency of construction project managers. Hanna et al. (2016) adopted an integrated mathematical approach to assess project managers' competency. Evaluation of project manager's competency can be seen as a multi-criteria decision making (MCDM) problem which refers to the problem of selecting alternatives associated with multiple criteria (Figueira, Greco, \& Ehrgott, 2005). Many methods have been developed to solve MCDM problems (Ji, Zhang, \& Wang, 2018; Peng, Wang, Hu, \& Tian, 2018; X. K. Wang, J. Y. Wang, \& Zhang, 2018; Wang, Peng, Zhang, \& Chen, 2019). The above methods are all based on expected utility theory and their assumption is that decision makers are completely rational which is obviously not realistic. During the process of decision making, the behavior of evaluator can have an influence on the decision making. A large number of behavioral economics experiments show that economic individuals are not completely rational, but bounded rational in decision making. Decision makers are frequently influenced by psychological factors related to bound rationality such as framing effect, reference dependence, loss aversion and etc. during the evaluating process. The TODIM (an acronym in Portuguese of interactive and multiple criteria decision making) method was proposed by Gomes and Lima (1992a, 1992b) and is a kind of behavior decision making method based on Prospect Theory (Kahneman \&Tversky, 1979). Simply speaking, TODIM is a method developed to solve ranking problems. It is used to solve problems related to multiple criteria decision making (MCDM), which consider decision maker's behavior and the criterion values are showed in the form of crisp numbers (Krohling, Pacheco, \& Siviero, 2013; Fan, Zhang, Chen, \& Liu, 2013; Zhang \& Fan, 2011).

When evaluating the project manager's competency, one interesting thing is that there is some degree of interactive characteristic among decision criteria. For instance, leadership and managerial skills are the two important criteria to evaluate project manager's competency. Generally, managers with higher leadership are more likely to direct their subordinates to complete some certain task. That is to say, leadership and managerial skills are not completely independent criteria. Besides, experience and professional skills are another two critical criteria which are not completely independent yet. For a certain project manager, his professional skills increase gradually with the accumulation of experience and knowledge. It is proved that fuzzy measure and Choquet integral are useful tools to deal with criteria interaction (Choquet, 1953). Fuzzy measure was introduced by Sugeno in 1974 to model the interaction phenomena among decision criteria (Kojadinovic, 2003) and was used to deal with the MCDM problems with interactive decision criteria (Grabisch, 1997; Grabisch, Murofushi, \& Sugeno, 2000; Ishii \& Sugeno, 1985; Nie, Tian, Wang, \& Hu, 2019). Since fuzzy measure was defined on the power set, it is difficult to obtain the fuzzy measure of each combination of a set when it is large and the computation process is exponentially complex (Meng, Zhang, $\&$ Cheng, 2013). In order to solve the problem, $\lambda$-fuzzy measure, which is a special kind of fuzzy measures, was proposed and has been widely used in MCDM (Tan, Jiang, \& Chen, 2015). Choquet integral which was proposed by Murofushi and Sugeno (1993), was one of the most important fuzzy integrals and had been widely used to measure the expected utility of the uncertain event (Meng et al., 2013). Choquet integral operator was used by many researchers to model interaction phenomena in decision making and fuzzy measure was used to define weight of each combination of criteria in Choquet integral operator based MCDM method (Joshi \& Kumar, 2016). Some extended TODIM methods were proposed to deal with interactive multicriteria decision making problem based on the $\lambda$-fuzzy measure and Choquet integral (Tan et al., 2015). However, these TODIM methods still can't handle MCDM problems with incomplete criteria information.

Among the existing methods of project manager's competency evaluation, few studies consider the interactions between criteria. At the same time, the bounded rational behaviors of decision makers are rarely taken into account. In this paper, an improved TODIM method which combines $\lambda$-fuzzy measure (Sugeno, 1974) with Choquet integral (Marichal, 2000; Tan, 2011) is proposed to evaluate project manager's competency considering criteria interaction and incomplete information about project manager's competency, and decision maker's bounded rational behaviors.

The rest of the paper is organized as follows: in Section 1, a literature review is conducted to summarize the related studies. In Section 2, some related concepts about fuzzy measure and Choquet integral are briefly reviewed. And the classical TODIM method is introduced. In Section 3, an extended TODIM method based on fuzzy measure and Choquet integral is proposed to evaluate the project manager's competency. In Section 4, a numerical example is given to illustrate the proposed approach. Finally, comparisons of related approaches are made, along with a discussion about the proposed method. Conclusions are presented at the end of paper.

\section{Literature review}

\subsection{Competency model of project manager}

The term "competency" is a person-related concept that refers to the dimensions of behavior action underlying superior rather than average performance (Cheng, Dainty, \& Moore, 2005; Toney \& Powers, 1997; Toney, 2001). When applied to project management, a competency is a dem- 
onstrated ability to perform activities exceptionally within a project's dynamic environment that leads to the expected outcomes based on defined and accepted standards (Crawford \& Arch, 1997). To evaluate the competency of project manager, competency model is widely used.

Competency model is a combination of competency structure for the performance of a particular position. S. Spencer and L. M. Spencer (1993) proposed the iceberg model and onion model, which are the main theoretical basis for studying the model of competency. With the project manager playing an increasingly important role in project management, more and more evaluation models of project manager are proposed by the researchers. One of the earliest scholars proposing essential profiles for the ideal project manager is Gaddis (1959) who emphasized that a competent project manager needs a solid experience base in the relevant field in and should also own such abilities as leadership, planning and executive skills. Russell et al. (1997) pointed out that project managers must have both traditional functions but also other non-professional knowledge and skills. Edum-Fotwe and McCaffer (2000) argued that traditional engineering requirement were not efficient for the project managers and pointed out that general knowledge and skill element are basic for developing project manager's competency. Meredith and Mantel Jr. (2011) suggested that the competency of project manager should include communication, organization, team building, leadership, response and professional skills. El-Sabaa (2001) made a conclusion that project manager differed greatly from the functional managers in such aspects as the attributes, skills, and experiences, and proposed a conceptual framework to select the effective project managers and improve their management performance. Markus, Thomas, and Allpress (2005) divided the definition of competency into three categories which are educational approach, psychological approach and organizational approach after making a literature review of related studies and analyzed how the competency model applied in New Zealand. Mül- ler and Turner (2007) studied the interaction between the leadership style of the project managers and project type and analyzed their common impact on the success of the project. Fisher (2011) identified six key capabilities and associated behavior, which included behavioral understanding, leadership, influence, real important behavior, conflict management ability, and cultural awareness, as being the most important factors for the successful delivery of project. Construction Industry Institute - Research Team 281 [CII-RT 281] (2012) developed a list of 14 competencies which were divided into four primary areas: technical/virtual, management, cognitive, and leadership. Zhang (2015) showed that personal qualities of project managers include cooperation, self-confidence, self-control, adaptability, open-minded mentality, situational insight, the ability to anticipate and analyze and the ability to judge. Hanna et al. (2016) proposed a generic mathematical formulation to weigh the competency of the project manager in the construction industry and suggested that the competency of project manager included not only such skills as adequate knowledge and experience, managerial capabilities and leadership skills, but should also have cognitive intelligence and personal traits. Maaleki and Cyrus (2017) presented ANP (the Analytic Network Process) method as one of the multi-criteria decision making (MCDM) methods to assess qualification of a construction manager and took personal skills, personal typicality, power, knowledge and specialty, experience as key factors to select the competent managers.

Based upon existing studies focusing on key elements or factors of project manager's competency showed in Table 1, it can be seen that four factors such as experience, professional skills, leadership and managerial skills are often used by the researchers to assess the competency of the project managers. Besides, some researchers pointed out that personal criteria or traits of a project manager were also very important for the success of project and considerable researches had been carried out on so called "personal

Table 1. Existing studies focusing on key elements or factors of project manager's competency

\begin{tabular}{|l|l|}
\hline \multicolumn{1}{|c|}{ Author } & \multicolumn{1}{|c|}{ Key elements or factors of project manager's competency } \\
\hline Gaddis (1959) & Experience in the relevant field, leadership skills, planning skills and executive skills \\
\hline Russell et al. (1997) & Non-professional knowledge and skills \\
\hline Edum-Fotwe and McCaffer (2000) & Knowledge and skills acquired through experience \\
\hline Meredith and Mantel Jr. (2011) & Communication, organization, team building, leadership, response and professional skills \\
\hline El-Sabaa (2001) & Human skills, conceptual and organizational skills, technical skills \\
\hline Markus et al. (2005) & Educational, psychological, business \\
\hline Müller and Turner (2007) & Leadership style \\
\hline Fisher (2011) & $\begin{array}{l}\text { Behavioral understanding, leadership, influence, real important behavior, conflict } \\
\text { management ability, cultural awareness }\end{array}$ \\
\hline CII-RT 281 (2012) & Technical/virtual, management, cognitive, and leadership \\
\hline Hanna et al. (2016) & $\begin{array}{l}\text { Managerial capabilities, leadership skills, technical knowledge, cognitive intelligence, } \\
\text { personal traits }\end{array}$ \\
\hline Maaleki and Cyrus (2017) & Personal skills, personal typicality, power, knowledge, specialty, experience \\
\hline
\end{tabular}


competency" (Turner, 1999; Ogunlana, Siddiqui, Yisa, \& Olomolaiye, 2002; Kohli \& Chitkara, 2007) which meant the individual characteristic or trait that people brought to their work roles, and was typically used in the processes of employee selection and performance management (Othman \& Jaafar, 2013). Then it can be concluded that personal trait or criterion is a key factor of project manager's competency. Thus, we build the competency model of project manager which includes such five factors as experience, personal traits, professional skills, leadership and managerial skills based upon the analysis above.

\subsection{Choquet integral and TODIM method}

Recently, Choquet integral based methods have received more and more attention and are successful used in dealing with the related information. TODIM method which was proposed by Gomes and Lima (1992a, 1992b) has been widely used to solve the MCDM problem and used as a kind of behavior decision making method based on the Prospect theory considering the decision makers' psychological behavior. Some extended TODIM methods have been proposed from different aspect. Zhang and Fan (2011) gave a language TODIM decision method with criterion information as language scale. Fan et al. (2013) proposed a hybrid multi-criteria TODIM decision method with criterion information as real number, interval number and fuzzy number. Zhang and $\mathrm{Xu}$ (2014) proposed a TODIM decision-making method based on hesitant fuzzy information, and applied it to the evaluation and ranking of Taiwan airline service quality. Jiang, Liang, and Zhang (2015) proposed a TODIM decision method with incomplete information for evaluations. On the basis of incomplete criterion information, Gao, Zhu, Z. Li, and W. Li (2015) proposed a TODIM method for threat evaluation of early warning detection. The above studies are based on the fact that the criteria of the evaluation objects are independent of each other. However, in the actual decision-making process, the criteria are not independent, but have certain relevance. So it is necessary to take into consideration the interaction among criteria in MCDM framework. Gomes (2009), Gomes, Machado, and Rangel (2013a), Gomes, Machado, Costa, and Rangel (2013b) proposed a multi-criteria decision making method that combines Choquet integrals with TODIM method taking criteria interactions into consideration. Tan et al. (2015) developed an extended Choquet-based TODIM method to deal with the hesitant fuzzy MDCM problems. Lourenzutti, Krohling, and Reformat (2017) proposed Choquet based TOPSIS and TODIM for dynamic and heterogeneous decision making with criteria interaction. The combination of Choquet integral and Heronian mean have been used to solve MCDM problem with correlated information. Peng et al. (2018) proposed the multi-valued neutrosophic geometric weighted Choquet integral Heronian mean (MVNGWCIHM) operator and used it to deal with multi-valued neutrosophic information in multi-criteria decision-making.

\section{Preliminary (Basic concept)}

\section{1. $\lambda$-fuzzy measure}

Definition 1 (Sugeno, 1974): Let $X=\left\{x_{1}, x_{2}, \cdots, x_{n}\right\}$ be a fixed set, $P(X)$ be the power set of $X$. A fuzzy measure on $X$ is a set function $\mu: P(X) \rightarrow[0,1]$, satisfying the following conditions:

(1) $\mu(\varnothing)=0, \mu(X)=1$;

(2) If $A, B \in P(X)$ and $A \subseteq B$, then $\mu(A) \leq \mu(B)$.

Fuzzy measure is often used to describe the three types of interaction phenomena among criteria: independency, complementarity or redundancy (Marichal, 2000).

$\lambda$-fuzzy measure which was proposed by Sugeno (1974) is special kind of fuzzy measure satisfying the following additional condition:

$$
\mu(A \cup B)=\mu(A)+\mu(B)+\lambda \mu(A) \mu(B),
$$

where $-1<\lambda<\infty$ for all $A, B \in P(X)$ and $A \cap B=\phi$.

Let $X=\left\{x_{1}, x_{2}, \cdots, x_{n}\right\}$ be a fixed set, $\mu$ is a $\lambda$-fuzzy measure on $X$. For $\forall A \in P(X), \lambda$-fuzzy measure can be calculated by using the following equation:

$$
\mu(A)= \begin{cases}\frac{1}{\lambda}\left(\prod_{x_{j} \in A}\left[1+\lambda \mu\left(x_{j}\right)\right]-1\right) & \text { if } \lambda \neq 0, \\ \sum_{x_{j} \in A} \mu\left(x_{j}\right) & \text { if } \lambda=0 .\end{cases}
$$

Especially, if $\mu(A)=1$, the Eqn (1) can be simplified as follows:

$$
\lambda+1=\prod_{j=1}^{m}\left[1+\lambda \mu\left(x_{j}\right)\right], \quad-1<\lambda<\infty, \lambda \neq 0 .
$$

It can be seen that the value of the parameter $\lambda$ can be uniquely determined by Eqn (2).

\subsection{Choquet integral}

Definition 2 (Grabisch et al., 2000): if $f$ is a non-negative function on $X=\left\{x_{1}, x_{2}, \cdots, x_{n}\right\}, \mu$ is a fuzzy measure on $X$, then the discrete Choquet integral of $f$ about the fuzzy measure $\mu$ is defined as follows:

$$
\begin{aligned}
& C I_{\mu}\left(f\left(x_{1}\right), f\left(x_{2}\right), \cdots, f\left(x_{m}\right)\right)= \\
& \sum_{j=1}^{m} f\left(x_{\sigma(j)}\right)\left[\mu\left(A_{\sigma(j)}\right)-\mu\left(A_{\sigma(j+1)}\right)\right],
\end{aligned}
$$

where $\sigma(\cdot)$ is a permutation on $X$ such that $0 \leq f\left(x_{\sigma(1)}\right) \leq f\left(x_{\sigma(2)}\right) \leq \cdots \leq f\left(x_{\sigma(m)}\right)$, and $A_{\sigma(j)}=$ $\left\{x_{\sigma(j)}, x_{\sigma(j+1)}, \cdots, x_{\sigma(m)}\right\}, A_{\sigma(m+1)}=\varnothing, f\left(x_{\sigma(0)}\right)=0$.

\subsection{The classical TODIM method}

Let $M=\{1,2, \ldots, m\}$ and $N=\{1,2, \ldots, n\}$. Let $A=\left\{A_{1}, A_{2}, \ldots, A_{m}\right\}$ be a finite set of alternative, where 
$A_{i}$ represents the $i$ th alternative; $C=\left\{C_{1}, C_{2}, \ldots, C_{n}\right\}$ be a finite set of criteria, where $C_{j}$ represents the $j$ th criterion; $w=\left(w_{1}, w_{2}, \ldots, w_{n}\right)^{T}$ be an criterion weight vector, where $w_{j}$ represents the weight of criterion $C_{j}$. According to the evaluated results from alternative $A_{i}$ with respect to criterion $C_{j}$, the decision makers obtain the decision matrix $P=\left[p_{i j}\right]_{m \times n}$, where $p_{i j}$ is the criterionvalue, $i \in M, j \in N$. The decision-making steps for the classical TODIM method are summarized as follows.

Step 1: transform the decision matrix $P=\left[p_{i j}\right]_{m \times n}$ into the normalized decision matrix $D=\left[d_{i j}\right]_{m \times n} \begin{aligned} & { }_{m \times n} \\ & \text { using }\end{aligned}$ the normalization method.

Step 2: calculate the relative weight $w_{j r}$ between the generic criterion $C_{j}$ and the reference criterion $C_{r}$ :

$$
w_{j r}=\frac{w_{j}}{w_{r}} \quad j \in N,
$$

where $w_{r}=\max \left\{w_{j} \mid j \in N\right\}$.

Step 3: calculate the dominance degree $\phi_{j}\left(A_{i}, A_{k}\right)$ of alternative $A_{i}$ over alternative $A_{k}$ concerning criterion $C_{j}$ :

$$
\begin{aligned}
& \phi_{j}\left(A_{i}, A_{k}\right)= \\
& \sqrt{\left(d_{i j}-d_{k j}\right) w_{j r} / \sum_{j=1}^{n} w_{j r},} \quad d_{i j}-d_{k j}>0, \\
& 0, \\
& -\frac{1}{\theta} \sqrt{\left(d_{k j}-d_{i j}\right)\left(\sum_{j=1}^{n} w_{j r}\right) / w_{j r},} \quad d_{i j}-d_{k j}<0 .
\end{aligned}
$$$$
i, k \in M, \quad j \in N,
$$

$\theta$ denotes the attenuation factor of the losses, and $\theta>0$. $d_{i j}-d_{k j}$ is the gain comparing alternative $A_{i}$ with alternative $A_{k}$ concerning criterion $C_{j}$ if $d_{i j}-d_{k j}>0$ and the loss if $d_{i j}-d_{k j}<0$.

Step 4: calculate the global dominance degree of alternative $A_{i}$ :

$$
\delta\left(A_{i}, A_{k}\right)=\sum_{j=1}^{n} \phi_{j}\left(A_{i}, A_{k}\right), \quad i \in M .
$$

Step 5: calculate the global value of alternative $A_{i}$ :

$$
\begin{aligned}
& T\left(A_{i}\right)= \\
& \frac{\sum_{k=1}^{m} \delta\left(A_{i}, A_{k}\right)-\min _{i \in M}\left\{\sum_{k=1}^{m} \delta\left(A_{i}, A_{k}\right)\right\}}{\max _{i \in M}\left\{\sum_{k=1}^{m} \delta\left(A_{i}, A_{k}\right)\right\}-\min _{i \in M}\left\{\sum_{k=1}^{m} \delta\left(A_{i}, A_{k}\right)\right\}}, \quad i \in M .
\end{aligned}
$$

Step 6: rank all the alternatives and select the optimal one(s) according to the global values of alternatives.

\section{Evaluation model of project manager's competency based on Choquet integral and TODIM method}

\subsection{Description of project manager's competency evaluation with incomplete attributes information}

To select a suitable project manager, a team composed of some human resources management specialists are invited to evaluate alternatives. Generally speaking, these specialists have the bounded rationality preference such as reference dependence and loss aversion. Let $A=\left\{A_{1}, A_{2}, \cdots, A_{i}, \cdots, A_{m}\right\}$ be the set of project manager, where $A_{i}$ represents the $i$-th alternative project manager. Moreover, let $C=\left\{C_{1}, C_{2}, \cdots, C_{j}, \cdots, C_{n}\right\}$ be a set of criteria derived by specialists through the Delphi method, where $C_{j}$ represents the $j$-th criterion. Meanwhile let $W=\left\{w_{1}, w_{2}, \cdots, w_{j}, \cdots, w_{n}\right\}$ be the set of criteria weight, where $w_{j}$ represents the weight of criteria $C_{j}$. Thus, the decision matrix is

$$
P=\left[P_{i j}\right]_{m \times n},
$$

where $P_{i j}$ is the value of the criteria $C_{j}$ for the alternative $A_{i}$.

What should be considered in the process of real decision making is that the criteria of project manager's competency are inter-dependence or interactive and the values of criteria are incomplete. There are five situations when the value of criteria information is incomplete which is shown as follows:

1) $P_{i j} \geq \lambda{ }_{i k}^{j} P_{k j}, i, k=1,2,3, \cdots, m, i \neq k, j=1,2,3, \cdots, n$;

2) $P_{i j}-P_{k j} \geq \varepsilon_{i k}^{j}, i, k=1,2,3, \cdots, m, i \neq k, j=1,2,3, \cdots, n$;

3) $P_{i j}-P_{k j} \geq P_{l j}-P_{h j}, i, k, l, h=1,2,3, \cdots, m$,

$i \neq k \neq l \neq h, j=1,2,3, \cdots, n$;

4) $\alpha_{i j}^{-} \leq P_{i j} \leq \alpha_{i j}^{+}, i, k=1,2,3, \cdots, m, j=1,2,3, \cdots, n$;

5) $\mu_{i j}^{-} P_{k j} \leq P_{i j} \leq \mu_{i j}^{+} P_{k j}, i, k=1,2,3, \cdots, m$,

$$
i \neq k, j=1,2,3, \cdots, n
$$

for any $i, k, j$, there is $\varepsilon_{i k}^{j}, \alpha_{i j}^{-}, \alpha_{i j}^{+} \in(0,1)$, and $\lambda_{i k}^{j}, \mu_{i j}^{-}, \mu_{i j}^{+}$ are positive real numbers.

\subsection{The evaluation approach of project manager's competency}

The flowchart of the proposed evaluation approach of project manager's competency using Choquet integral and TODIM method is shown in Figure 1. From Figure 1, we can see the process of decision making by using the extended TODIM method.

First, the values of criteria are given by decision makers and information about criteria is incomplete. Next, the relative weights of criteria will be determined by using the Choquet integral and the interactive of the criteria will be considered. Then, the dominance degree of alternative 
$A_{i}$ over $A_{k}$ concerning criteria $C_{j}$ will be calculated. An optimization model is constructed to maximize the sum of overall dominance degree subject to the constraint of the incomplete information about criteria. After solving the optimization model, the decision matrix with accurate criteria value can be obtain. Finally, the ranking order of alternatives according to the overall values can be determined.

The main steps of the evaluation approach of project manager's competency based on the extended TODIM method which combines $\lambda$-fuzzy measure with Choquet integral considering incomplete criteria information is as follows.

Step 1: normalize the decision matrix.

When evaluating the competency of project managers, different types of criteria, such as benefit type, cost type, fixed type and interval type, may be used by the decision makers. We should transform different types of criteria into one uniform type, which means to transform decision matrix $P$ to normalization decision matrix $B$ using the following equation:

$$
P=\left[P_{i j}\right]_{m \times n} \rightarrow B=\left[B_{i j}\right]_{m \times n},
$$

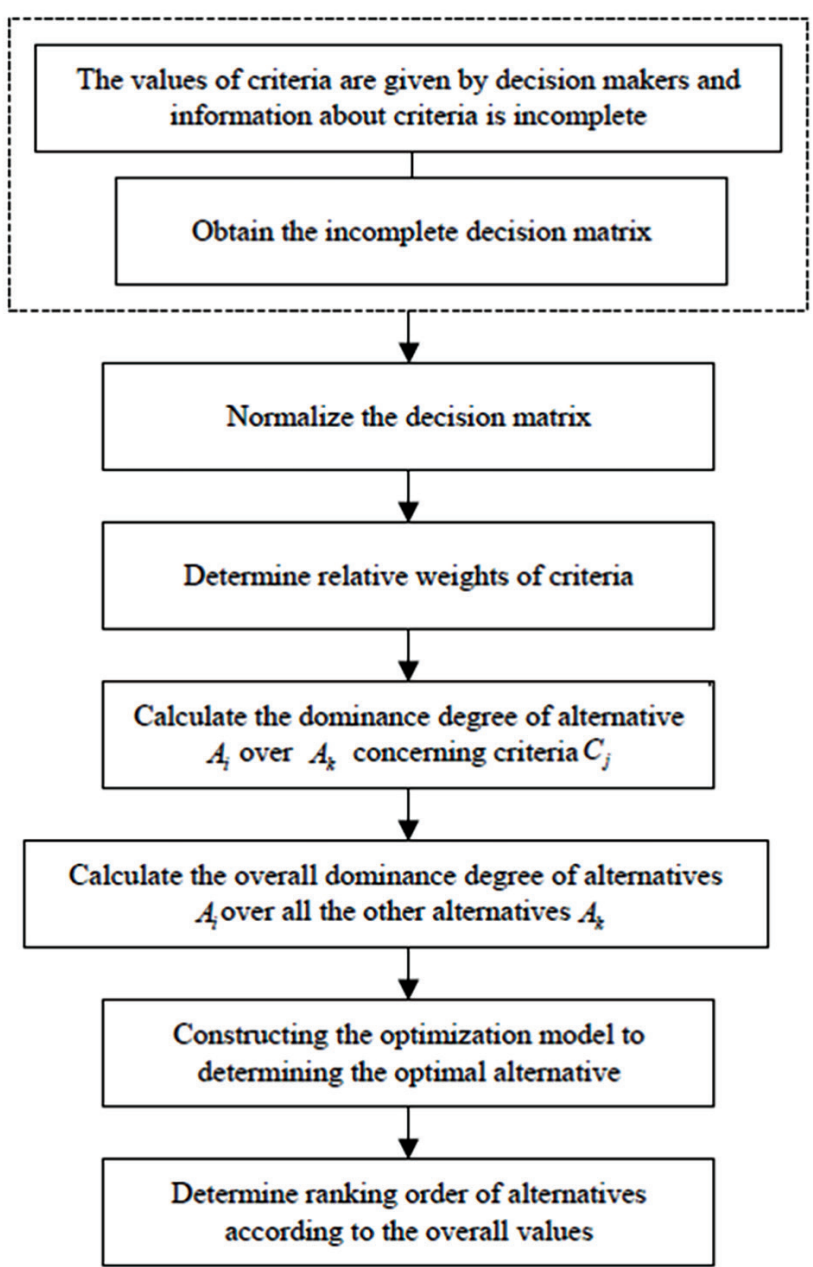

Figure 1. The framework of the proposed method
Let

$P_{j}^{+}=\max \left\{P_{i j} \mid i=1,2,3, \cdots, m\right\}, P_{j}^{-}=\min \left\{P_{i j} \mid i=1,2,3, \cdots, m\right\}$,

$P_{j}^{*}$ is a fixed value of $C_{j}$. The different transformation equation are shown as follows:

(1) For benefit types, the normalization equation is:

$$
B_{i j}=\frac{P_{i j}-P_{j}^{-}}{P_{j}^{+}-P_{j}^{-}}, i=1,2,3, \cdots, m, j=1,2,3, \cdots, n .
$$

(2) For cost types, the normalization equation is:

$$
B_{i j}=\frac{P_{j}^{+}-P_{i j}}{P_{j}^{+}-P_{j}^{-}}, i=1,2,3, \cdots, m, j=1,2,3, \cdots, n .
$$

(3) For fixed types, the normalization equation is:

$$
B_{i j}=\left\{\begin{array}{cc}
1, & P_{i j}=P_{j}^{*}, \\
1-\frac{\left|P_{i j}-P_{j}^{*}\right|}{\delta^{+}}, & P_{i j} \neq P_{j}^{*},
\end{array}\right.
$$

where $i=1,2,3, \cdots, m, j=1,2,3, \cdots, n, \delta^{+}=\max \left|P_{i j}-P_{j}^{*}\right|$.

(4) For interval types, $P_{i j} \in\left[d_{j}^{-}, d_{j}^{+}\right]$, the normalization equation is:

$$
B_{i j}=\left\{\begin{array}{cc}
1-\frac{d_{j}^{-}-P_{i j}}{\beta_{j}^{+}}, & P_{i j}<d_{j}^{-}, \\
1, & P_{i j} \in\left[d_{j}^{-}, d_{j}^{+}\right], \\
1-\frac{P_{i j}-d_{j}^{+}}{\beta_{j}^{+}}, & P_{i j}<d_{j}^{-},
\end{array}\right.
$$

where $i=1,2,3, \cdots, m, \quad j=1,2,3, \cdots, n$,

$$
\beta_{j}^{+}=\max \left\{d_{j}^{-}-P_{j}^{-}, P_{j}^{+}-d_{j}^{+}\right\} .
$$

Step 2: determine the relative weights of criteria.

(1) Obtain the interactive measure between criteria.

Considering that criteria are interactive, it is necessary to obtain the interactive measure between criteria to determine the importance of each criterion subset. According to the definition of $\lambda$-fuzzy measure, let $\mu\left(C_{1}\right), \mu\left(C_{2}\right), \cdots, \mu\left(C_{n}\right)$ be the weight of criteria $C_{1}, C_{2}, \ldots, C_{n}$. The parameter $\lambda$ can be used to represent the interaction measure between criteria, which can be calculated based on Eqn (2) and shown as follows:

$$
\lambda+1=\prod_{j=1}^{m}\left[1+\lambda \mu\left(C_{j}\right)\right],-1<\lambda<\infty \text { and } \lambda \neq 0 .
$$

Then $\mu(U)$ can be calculated as follows, which means the importance of each criterion subset:

$$
\mu(U)=\frac{1}{\lambda}\left(\prod_{C_{j} \in U}\left[1+\lambda \mu\left(C_{j}\right)\right]-1\right), \quad U \in P(C),
$$

where $P(C)$ represents a power set of $C=\left\{C_{1}, C_{2}, \cdots, C_{n}\right\}$.

(2) Calculate additive weights of criteria.

The gain and loss of alternative project manager $A_{i}$ relative to $A_{k}$ with respect to criteria $C_{1}, C_{2}, \cdots, C_{n}$ is defined as $B_{i 1}-B_{k 1}, B_{i 2}-B_{k 2}, \cdots, B_{i j}-B_{k j}, \cdots, B_{i n}-B_{k n}$, 
which are rearranged in ascending order based on the definition of Choquet integral and the result is obtained as $B_{i(1)}-B_{k(1)} \leq B_{i(2)}-B_{k(2)} \leq \cdots \leq B_{i(j)}-B_{k(j)} \leq \cdots \leq B_{i(n)}-$

$B_{k(n)}$, where $B_{i(j)}-B_{k(j)}$ is the $j$-th largest gain and loss of alternative $A_{i}$ relative to $A_{k}$ concerning criteria $C_{\sigma(j)}$. The additive weight $w_{i k}^{(j)}$ of $B_{i(j)}-B_{k(j)}$ concerning criteria $C_{\sigma(j)}$ is calculated as follows:

$$
w_{i k}^{(j)}=\mu\left(U_{\sigma(j)}\right)-\mu\left(U_{\sigma(j+1)}\right),
$$

where $U_{\sigma(j)}=\left\{C_{\sigma(j)}, C_{\sigma(j+1)}, \cdots, C_{\sigma(n)}\right\}, \mu\left(U_{\sigma(j)}\right)$ is the importance degree of criterion subset $U_{\sigma(j)}$.

Therefore, we can obtain the set of weight vector $W_{i k}=\left\{w_{i k}^{(1)}, w_{i k}^{(2)}, \cdots, w_{i k}^{(n)}\right\} W_{i k}=\left\{w_{i k}^{(1)}, w_{i k}^{(2)}, \cdots, w_{i k}^{(n)}\right\}$. We can also obtain the set of weight $W_{i k}=\left\{w_{i k}^{1}, w_{i k}^{2}, \cdots, w_{i k}^{n}\right\}$ concerning the set of criteria $C=\left\{C_{1}, C_{2}, C_{3}, \cdots, C_{n}\right\}$.

(3) Calculate relative weight of criteria.

According the TODIM method, the relative weight $w_{i k}^{j^{*}}$ is calculated, which is the weight of criteria $C_{j}$ relative to the reference criteria when comparing alternative project manager $A_{i}$ with $A_{k}$ and is shown as follows:

where

$$
w_{i k}^{j^{*}}=\frac{w_{i k}^{j}}{w_{i k}^{*}}, \quad j=1,2, \cdots, n \quad i, k=1,2, \cdots, m, i \neq k,
$$

$$
w_{i k}^{*}=\max \left\{w_{i k}^{1}, w_{i k}^{2}, \cdots, w_{i k}^{n}\right\} .
$$

Therefore, the weight set of relative criteria $W_{i k}^{*}=\left\{w_{i k}^{1^{*}}, w_{i k}^{2^{*}}, \cdots, w_{i k}^{n^{*}}\right\}$ can be obtained.

Step 3: calculate the dominance degree of alternative project manager $A_{i}$ over $A_{k}$ concerning criteria $C_{j}$.

$\phi_{j}\left(A_{i}, A_{k}\right)$ which is the dominance degree of alternative project manager $A_{i}$ over $A_{k}$ concerning criteria $C_{j}$ can be calculated as follows:

$$
\phi_{j}\left(A_{i}, A_{k}\right)=\left\{\begin{array}{cc}
\sqrt{\left(B_{i j}-B_{k j}\right) w_{i k}^{j^{*}} / \sum_{j=1}^{n} w_{i k}^{j^{*}}}, & B_{i j}-B_{k j}>0, \\
0, & B_{i j}-B_{k j}=0, \\
-\frac{1}{\theta} \sqrt{\left(B_{k j}-B_{i j}\right) \sum_{j=1}^{n} w_{i k}^{j^{*}} / w_{i k}^{j^{*}}}, & B_{i j}-B_{k j}<0 .
\end{array}\right.
$$

Here $i, k=1,2,3, \cdots, m ; j=1,2,3, \cdots, n . \theta$ is the attenuation factor of the loss and represents the degree of the decision maker's loss-aversion, $\theta>0$. The smaller $\theta$ is, the higher the degree of loss aversion is.

$$
\begin{aligned}
& \text { If } B_{i j}-B_{k j}>0,\left|\sqrt{\left(B_{i j}-B_{k j}\right) w_{i k}^{j^{*}} / \sum_{j=1}^{n} w_{i k}^{j^{*}}}\right|< \\
& \left|-\frac{1}{\theta} \sqrt{\left(B_{k j}-B_{i j}\right) \sum_{j=1}^{n} w_{i k}^{j^{*}} / w_{i k}^{j^{*}}}\right|, \text { which indicates that deci- }
\end{aligned}
$$

sion makers are more concerned about losses when confronted with same gains and losses of the same value.

Step 4: calculate the overall dominance degree of alternatives over all the other alternatives.

For each criterion, overall dominance degree of alternative project manager $A_{i}$ over all the other alternative $A_{k}$ is calculated by using the equation as follows:

$$
\Phi\left(A_{i}, A_{k}\right)=\sum_{j=1}^{n} \phi_{j}\left(A_{i}, A_{k}\right),
$$

where $i, k=1,2,3, \cdots, m ; i \neq k$.

By comparing the alternative project managers in pairs, the overall dominance degree matrix about the alternatives can be obtained as follows:

$$
\Phi=\left[\begin{array}{ccccc}
0 & \Phi\left(A_{1}, A_{2}\right) & \Phi\left(A_{1}, A_{3}\right) & \Phi\left(A_{1}, A_{4}\right) & \Phi\left(A_{1}, A_{5}\right) \\
\Phi\left(A_{2}, A_{1}\right) & 0 & \Phi\left(A_{2}, A_{3}\right) & \Phi\left(A_{2}, A_{4}\right) & \Phi\left(A_{2}, A_{5}\right) \\
\Phi\left(A_{3}, A_{1}\right) & \Phi\left(A_{3}, A_{2}\right) & 0 & \Phi\left(A_{3}, A_{4}\right) & \Phi\left(A_{3}, A_{5}\right) \\
\Phi\left(A_{4}, A_{1}\right) & \Phi\left(A_{4}, A_{2}\right) & \Phi\left(A_{4}, A_{3}\right) & 0 & \Phi\left(A_{4}, A_{5}\right) \\
\Phi\left(A_{5}, A_{1}\right) & \Phi\left(A_{5}, A_{2}\right) & \Phi\left(A_{5}, A_{3}\right) & \Phi\left(A_{5}, A_{4}\right) & 0
\end{array}\right] .
$$

Let $T\left(A_{i}\right)$ be the overall dominance degree of alternative $A_{i}$ over all the other alternatives $A_{k}$, and it can be calculated as follows:

$$
T\left(A_{i}\right)=\sum_{k=1}^{m} \Phi\left(A_{i}, A_{k}\right), i=1,2,3, \cdots, m .
$$

Step 5: constructing the optimization model to determining the optimal alternative.

Obviously, the greater the overall dominance degree is, the better the alternative is. We can construct an optimization model to select the optimal alternative project manager which maximizes the overall dominance degree of alternative $A_{i}$ over all the other $A_{k}$, as follows:

$$
\max T\left(A_{i}\right)=\sum_{k=1}^{m} \sum_{j=1}^{n} \phi_{j}\left(A_{i}, A_{k}\right), i=1,2,3, \cdots, m,
$$

$$
\begin{cases}P_{i j} \geq \lambda_{i k}^{j} P_{k j}, & i, k=1,2,3, \cdots, m, i \neq k, j=1,2,3, \cdots, n \\ P_{i j}-P_{k j} \geq \varepsilon_{i k}^{j}, & i, k=1,2,3, \cdots, m, i \neq k, j=1,2,3, \cdots, n \\ P_{i j}-P_{k j} \geq P_{l j}-P_{h j}, & i, k, l, h=1,2,3, \cdots, m, i \neq k \neq l \neq h, j=1,2,3, \cdots, n . \\ \alpha_{i j}^{-} \leq P_{i j} \leq \alpha_{i j}^{+}, & i, k=1,2,3, \cdots, m, j=1,2,3, \cdots, n \\ \mu_{i j}^{-} P_{k j} \leq P_{i j} \leq \mu_{i j}^{+} P_{k j}, & i, k=1,2,3, \cdots, m, i \neq k, j=1,2,3, \cdots, n\end{cases}
$$

It is supposed that the decision makers have no preference for the alternatives. Let $S$ be the sum of the overall dominance degree for all alternatives, then the single-objective optimization model can be constructed which is to maximizes the value of $S$ :

$$
\max S=\sum_{i=1}^{m} T\left(A_{i}\right), i=1,2,3, \cdots, m,
$$

$$
\text { s.t. } \begin{cases}P_{i j} \geq \lambda_{i k}^{j} P_{k j}, & i, k=1,2,3, \cdots, m, i \neq k, j=1,2,3, \cdots, n \\ P_{i j}-P_{k j} \geq \varepsilon_{i k}^{j}, & i, k=1,2,3, \cdots, m, i \neq k, j=1,2,3, \cdots, n \\ P_{i j}-P_{k j} \geq P_{l j}-P_{h j}, & i, k, l, h=1,2,3, \cdots, m, i \neq k \neq l \neq h, j=1,2,3, \cdots, n . \\ \alpha_{i j}^{-} \leq P_{i j} \leq \alpha_{i j}^{+}, & i, k=1,2,3, \cdots, m, j=1,2,3, \cdots, n \\ \mu_{i j}^{-} P_{k j} \leq P_{i j} \leq \mu_{i j}^{+} P_{k j}, & i, k=1,2,3, \cdots, m, i \neq k, j=1,2,3, \cdots, n\end{cases}
$$


Therefore, the solution of the optimization model can be obtained by using MATLAB software. The criteria value $P_{i j}$ which satisfies the objective function and a decision matrix $P$ with complete criteria information can be obtained as follows:

$$
\left[\begin{array}{ccccc}
P_{11} & P_{12} & P_{13} & \cdots & P_{1 n} \\
P_{21} & P_{22} & P_{23} & \cdots & P_{2 n} \\
P_{31} & P_{32} & P_{33} & \cdots & P_{3 n} \\
\vdots & \vdots & \vdots & \ddots & \vdots \\
P_{m 1} & P_{m 2} & P_{m 3} & \cdots & P_{m n}
\end{array}\right]
$$

Step 6: determine the ranking order of alternatives according to the overall values.

The normalized overall value $S\left(A_{i}\right)$ of the alternatives $A_{i}$ can be calculated as follows:

$$
S\left(A_{i}\right)=\frac{T\left(A_{i}\right)-T\left(A_{i}\right)^{-}}{T\left(A_{i}\right)^{+}-T\left(A_{i}\right)^{-}}, i=1,2,3, \cdots, m,
$$

where $T\left(A_{i}\right)^{+}=\max \left\{T\left(A_{i}\right) \mid i=1,2,3, \cdots, m\right\}$,

$$
T\left(A_{i}\right)^{-}=\min \left\{T\left(A_{i}\right) \mid i=1,2,3, \cdots, m\right\} .
$$

Obviously, it can be found that $0 \leq S\left(A_{i}\right) \leq 1$, and the greater $S\left(A_{i}\right)$ is, the better the alternatives $A_{i}$ is. We can determine the ranking order of alternatives $A_{i}$ according to the obtained normalized overall value $S\left(A_{i}\right)$.

\section{A numerical example}

\subsection{Illustration of the proposed approach}

In order to illustrate how the proposed method can be applied in a real situation, a case study is presented. Suppose that a company is going to carry out a railway construction project and there are five alternatives (named as $\left.A_{1}, A_{2}, A_{3}, A_{4}, A_{5}\right)$ applying for the position of project manager. To select the suitable project manager, several human resource professionals are invited to evaluate the alternative s' competency. Based on the Delphi method, five criteria are selected to use as evaluation index including experience $\left(C_{1}\right)$, personal traits $\left(C_{2}\right)$, professional skills $\left(C_{3}\right)$, leadership $\left(C_{4}\right)$, and managerial skills $\left(C_{5}\right)$. From the analysis, it can be concluded that these five criteria belong to benefit type and they are interrelated. The weight set is $W=\{0.8,0.6,0.3,0.5,0.4\}$. Decision makers have the preference for bounded rational behaviors such as reference dependence and loss aversion when they are facing different kinds of uncertainties. Therefore, it is assumed that evaluation information about criteria given by decision makers is all incomplete and is shown in Table 2 and the incomplete decision matrix $P=\left[P_{i j}\right]_{m \times n}$ for deci-
sion making can be obtained.

The extended TODIM method based on $\lambda$-fuzzy measure and Choquet integral for evaluating project managers' competency is shown as follows.

Step1: obtain the normalized decision matrix.
The normalized decision matrix can be obtained, which means to transform decision matrix $P$ into normalized decision matrix $B$ using the Eqns (6)-(9),

$$
P=\left[P_{i j}\right]_{m \times n} \rightarrow B=\left[B_{i j}\right]_{m \times n} .
$$

Let $P_{j}^{+}=\max \left\{P_{i j} \mid i=1,2,3, \cdots, m\right\}$, $C_{j}$

$$
P_{j}^{-}=\min \left\{P_{i j} \mid i=1,2,3, \cdots, m\right\}, P_{j}^{*} \text { is a fixed value of }
$$

Because the five criteria are all benefit types, the transformation equation is

$$
B_{i j}=\frac{P_{i j}-P_{j}^{-}}{P_{j}^{+}-P_{j}^{-}}, i=1,2,3, \cdots, m, j=1,2,3, \cdots, n .
$$

Step 2: determine relative weights of criteria.

According to Eqn (11), the importance degree $\mu\left(U_{\sigma(j)}\right)$ of each criterion subset $U_{\sigma(j)}$ and the additive weight of $B_{i(j)}-B_{k(j)}$, which is the profit and loss of alternative $A_{i}$ relative to $A_{k}$ with respect to criteria $C_{1}, C_{2}, \cdots, C_{n}$, can be calculated as follows:

$$
\begin{aligned}
& w_{12}^{1}=\mu\left(U_{\sigma(1)}\right)-\mu\left(U_{\sigma(2)}\right) \\
& w_{12}^{2}=\mu\left(U_{\sigma(2)}\right)-\mu\left(U_{\sigma(3)}\right) ; \\
& w_{12}^{3}=\mu\left(U_{\sigma(3)}\right)-\mu\left(U_{\sigma(4)}\right) ; \\
& w_{12}^{4}=\mu\left(U_{\sigma(4)}\right)-\mu\left(U_{\sigma(5)}\right) ; \\
& w_{12}^{5}=\mu\left(U_{\sigma(5)}\right)-\mu\left(U_{\sigma(6)}\right) .
\end{aligned}
$$

Then, we can obtain the weight set $\left(w_{12}=\{0.012,0.119,0.216,0.353,0.300\}\right)$ of alternative $A_{1}$ relative to alternative $A_{2}$, and the parameter $\lambda$ can be calculated by using Eqn (10):

$$
\lambda+1=(1+0.8 \lambda)(1+0.6 \lambda)(1+0.3 \lambda)(1+0.5 \lambda)(1+0.4 \lambda) .
$$

So $\lambda=-0,98$ can be obtained and the importance degree $\mu\left(U_{\sigma(j)}\right)$ of each criterion subset $U_{\sigma(j)}$ is shown in

$$
\begin{aligned}
& w_{12}^{*}=\max \{0.012,0.119,0.216,0.353,0.300\}=0.353 \\
& w_{12}^{1^{\prime}}=\frac{w_{12}^{1}}{w_{12}^{*}}=\frac{0.012}{0.353}=0.035 \\
& w_{12}^{2^{\prime}}=\frac{w_{12}^{2}}{w_{12}^{*}}=\frac{0.119}{0.353}=0.336 ; \\
& w_{12}^{3^{\prime}}=\frac{w_{12}^{3}}{w_{12}^{*}}=\frac{0.216}{0.353}=0.612 ; \\
& w_{12}^{4^{\prime}}=\frac{w_{12}^{4}}{w_{12}^{*}}=\frac{0.353}{0.353}=1.000 ; \\
& w_{12}^{5^{\prime}}=\frac{w_{12}^{5}}{w_{12}^{*}}=\frac{0.300}{0.353}=0.850 .
\end{aligned}
$$


Table 2. Evaluation information about criteria given by the decision makers

\begin{tabular}{|c|c|c|c|c|c|}
\hline Criteria & $C_{1}$ & $C_{2}$ & $C_{3}$ & $C_{4}$ & $C_{5}$ \\
\hline$A_{1}$ & $P_{11}>70$ & $P_{12}=P_{31}$ & $P_{13}=1.05 P_{31}$ & $P_{14}>80$ & $P_{15} \leq 80$ \\
\hline$A_{2}$ & 90 & $P_{22}>85$ & $P_{23} \geq 80$ & $P_{24}>1.02 P_{14}$ & $P_{25} \geq 85$ \\
\hline$A_{3}$ & $P_{31}>75$ & $P_{32}<0.95 P_{42}$ & $P_{33}>75$ & 80 & \\
\hline & 70 & 88 & 80 & 80 & 78 \\
\hline
\end{tabular}

Table 3. Importance of each criterion subset

\begin{tabular}{|c|c|c|c|c|c|}
\hline Subset & Weight & Subset & Weight & Subset & Weight \\
\hline$\phi$ & 0.000 & $\left\{C_{1}\right\}$ & 0.800 & $\left\{C_{2}\right\}$ & 0.600 \\
\hline$\left\{C_{3}\right\}$ & 0.300 & $\left\{C_{4}\right\}$ & 0.500 & $\left\{C_{5}\right\}$ & 0.400 \\
\hline$\left\{C_{1}, C_{2}\right\}$ & 0.930 & $\left\{C_{1}, C_{3}\right\}$ & 0.865 & $\left\{C_{1}, C_{4}\right\}$ & 0.908 \\
\hline$\left\{C_{1}, C_{5}\right\}$ & 0.886 & $\left\{C_{2}, C_{3}\right\}$ & 0.724 & $\left\{C_{2}, C_{4}\right\}$ & 0.806 \\
\hline$\left\{C_{2}, C_{5}\right\}$ & 0.765 & $\left\{C_{3}, C_{4}\right\}$ & 0.653 & $\left\{C_{3}, C_{5}\right\}$ & 0.582 \\
\hline$\left\{C_{4}, C_{5}\right\}$ & 0.704 & $\left\{C_{1}, C_{2}, C_{3}\right\}$ & 0.956 & $\left\{C_{1}, C_{2}, C_{4}\right\}$ & 0.974 \\
\hline$\left\{C_{1}, C_{2}, C_{5}\right\}$ & 0.965 & $\left\{C_{1}, C_{3}, C_{4}\right\}$ & 0.941 & $\left\{C_{1}, C_{3}, C_{5}\right\}$ & 0.926 \\
\hline$\left\{C_{1}, C_{4}, C_{5}\right\}$ & 0.952 & $\left\{C_{2}, C_{3}, C_{4}\right\}$ & 0.869 & $\left\{C_{2}, C_{3}, C_{5}\right\}$ & 0.840 \\
\hline$\left\{C_{2}, C_{4}, C_{5}\right\}$ & 0.890 & $\left\{C_{3}, C_{4}, C_{5}\right\}$ & 0.797 & $\left\{C_{1}, C_{2}, C_{3}, C_{4}\right\}$ & 0.988 \\
\hline$\left\{C_{1}, C_{2}, C_{3}, C_{5}\right\}$ & 0.981 & $\left\{C_{1}, C_{2}, C_{4}, C_{5}\right\}$ & 0.992 & $\left\{C_{1}, C_{3}, C_{4}, C_{5}\right\}$ & 0.972 \\
\hline$\left\{C_{2}, C_{3}, C_{4}, C_{5}\right\}$ & 0.928 & $\left\{C_{1}, C_{2}, C_{3}, C_{4}, C_{5}\right\}$ & 1.000 & & \\
\hline
\end{tabular}

Therefore, the relative weight set of criterion when comparing alternative $A_{1}$ with $A_{2}$ is $w_{12}^{\prime}=\{0.035,0.336,0.612,1.000,0.850\}$.

In the same way, the relative weight $w_{i k}^{j^{*}}$ is calculated by using Eqn (13), which is the weight of criteria $C_{j}$ relative to the reference criteria when comparing alternative $A_{i}$ with $A_{k}$ and is shown as follows:

$$
\begin{aligned}
& w_{13}^{\prime}=\{0.203,0.372,0.408,1.000,0.850\} ; \\
& w_{14}^{\prime}=\{0.056,0.062,0.576,0.306,1.000\} ; \\
& w_{15}^{\prime}=\{0.203,0.372,0.408,1.000,0.850\} ; \\
& w_{21}^{\prime}=\{0.016,0.056,0.162,1.000,0.822\} ; \\
& w_{23}^{\prime}=\{0.015,0.204,0.372,0.408,1.000\} ; \\
& w_{24}^{\prime}=\{0.070,0.050,0.620,0.760,1.000\} ; \\
& w_{25}^{\prime}=\{0.179,0.328,0.233,0.760,1.000\} ; \\
& w_{31}^{\prime}=\{0.010,0.034,0.044,0.162,1.000\} ; \\
& w_{32}^{\prime}=\{0.033,0.044,0.162,1.000,0.531\} ;
\end{aligned}
$$

$w_{34}^{\prime}=\{0.035,0.025,0.082,0.108,1.000\} ;$

$w_{35}^{\prime}=\{0.062,0.472,0.858,0.941,1.000\}$;

$w_{41}^{\prime}=\{0.031,0.027,0.334,0.275,1.000\}$;

$w_{42}^{\prime}=\{0.020,0.052,0.388,0.206,1.000\}$;

$w_{43}^{\prime}=\{0.119,0.099,0.242,0.206,1.000\}$;

$w_{45}^{\prime}=\{0.169,0.209,0.275,1.000,0.708\}$;

$w_{51}^{\prime}=\{0.010,0.034,0.044,0.162,1.000\}$;

$w_{52}^{\prime}=\{0.015,0.039,0.033,0.162,1.000\}$;

$w_{53}^{\prime}=\{0.015,0.036,0.132,0.816,1.000\}$;

$w_{54}^{\prime}=\{0.010,0.050,0.055,0.135,1.000\}$.

Step 3: calculate the dominance degree matrix concerning criteria $C_{j}$.

According to the Eqn (16), the dominance degree matrix concerning criteria $C_{j}$ can be obtained as follows. It is supposed that the attenuation factor of loss $\theta$ is 1 . 


$$
\begin{aligned}
C_{1}: & \Phi_{1}=\left[\begin{array}{ccccc}
0.00 & -7.81 & -1.87 & 0.08 & -2.64 \\
0.08 & 0.00 & 0.06 & 0.17 & 0.13 \\
0.04 & -5.19 & 0.00 & 0.12 & -3.67 \\
-3.67 & -9.02 & -2.64 & 0.00 & -3.24 \\
0.06 & -4.51 & 0.04 & 0.08 & 0.00
\end{array}\right] ; \\
C_{2}: & {\left[\begin{array}{ccccc}
0.00 & -2.51 & -1.38 & -5.67 & -1.95 \\
0.14 & 0.00 & 0.23 & -3.53 & 0.18 \\
0.08 & -4.46 & 0.00 & -6.11 & -1.33 \\
0.13 & 0.09 & 0.21 & 0.00 & 0.21 \\
0.12 & -2.82 & 0.07 & -3.53 & 0.00
\end{array}\right] ; }
\end{aligned}
$$

$C_{3}:$

$$
\Phi_{3}=\left[\begin{array}{ccccc}
0.00 & 0.33 & 0.33 & 0.38 & 0.38 \\
-2.52 & 0.00 & 0.22 & 0.00 & 0.22 \\
-4.59 & -1.65 & 0.00 & -1.95 & 0.25 \\
-1.58 & 0.00 & 0.19 & 0.00 & 0.24 \\
-5.30 & -4.33 & -1.94 & -3.37 & 0.00
\end{array}\right] \text {; }
$$

$C_{4}:$

$$
\Phi_{4}=\left[\begin{array}{ccccc}
0.00 & -1.19 & 0.42 & 0.28 & 0.00 \\
0.49 & 0.00 & 0.45 & 0.55 & 0.39 \\
-1.96 & -1.33 & 0.00 & 0.00 & -1.33 \\
-1.74 & -2.84 & 0.00 & 0.00 & -1.09 \\
0.00 & -1.96 & 0.45 & 0.23 & 0.00
\end{array}\right] ;
$$

$C_{5}$ :

$$
\Phi_{5}=\left[\begin{array}{ccccc}
0.00 & -1.63 & -0.82 & 0.32 & -0.82 \\
0.57 & 0.00 & 0.55 & 0.63 & 0.49 \\
0.40 & -1.41 & 0.00 & 0.57 & 0.00 \\
-0.58 & -1.29 & -0.82 & 0.00 & -1.15 \\
0.40 & -0.87 & 0.00 & 0.57 & 0.00
\end{array}\right] .
$$

Step 4: calculate the overall dominance of alternative $A_{i}$ over $A_{k}$, the overall dominance degree matrix can be calculated as follows:

$$
\Phi=\left[\begin{array}{ccccc}
0.00 & -12.82 & -3.32 & -4.61 & -5.03 \\
-1.24 & 0.00 & 1.50 & -2.18 & 1.41 \\
-6.03 & -14.05 & 0.00 & -7.38 & -6.08 \\
-7.44 & -13.07 & -3.06 & 0.00 & -5.03 \\
-4.72 & -14.49 & -1.38 & -6.02 & 0.00
\end{array}\right] .
$$

So, the overall dominance degree of alternative $A_{i}$ over alternatives $A_{k}$ is calculated as follows:

$$
\begin{aligned}
& T\left(A_{1}\right)=\sum_{k=1}^{5} \Phi\left(A_{1}, A_{k}\right)=-25.78 ; \\
& T\left(A_{2}\right)=\sum_{k=1}^{5} \Phi\left(A_{2}, A_{k}\right)=-0.50 ; \\
& T\left(A_{3}\right)=\sum_{k=1}^{5} \Phi\left(A_{3}, A_{k}\right)=-33.53 ;
\end{aligned}
$$

$$
\begin{aligned}
& T\left(A_{4}\right)=\sum_{k=1}^{5} \Phi\left(A_{4}, A_{k}\right)=-28.59 ; \\
& T\left(A_{5}\right)=\sum_{k=1}^{5} \Phi\left(A_{5}, A_{k}\right)=-26.61 .
\end{aligned}
$$

Step 5: construct the optimization model which is to maximize the sum $S$ of the dominance degree for alternative $A_{i}$ to $A_{k}$ concerning criteria $C_{j}$ :

$$
\begin{aligned}
\max S=\sum_{i=1}^{5} \sum_{k=1}^{5} \sum_{j=1}^{5} \phi_{j}\left(A_{i}, A_{k}\right) ; & \text { s.t. }\left\{\begin{array}{ccccc}
P_{11}>70 & P_{12}=P_{31} & P_{13}=1.05 P_{31} & P_{14}>80 & P_{15} \leq 80 \\
P_{21}=90 & P_{22}>85 & P_{23} \geq 80 & P_{24}>1.02 P_{14} & P_{25} \geq 85 \\
P_{31}>75 & P_{32}<0.95 P_{42} & P_{33}>75 & P_{34}=80 & P_{35}<85 \\
P_{41}=70 & P_{42}=88 & P_{43}=80 & P_{44}=80 & P_{45}=78 \\
P_{51}>80 & P_{52}>80 & P_{13}-10<P_{53}<80 & P_{54}>P_{44} & P_{55}>P_{45}
\end{array} .\right.
\end{aligned}
$$

The optimization model can be solved by using MATLAB 7.8, and decision matrix $P$ are obtained:

$$
P=\left[\begin{array}{lllll}
75 & 80 & 84 & 82 & 80 \\
90 & 86 & 80 & 84 & 88 \\
80 & 82 & 78 & 80 & 82 \\
70 & 88 & 80 & 80 & 78 \\
85 & 84 & 76 & 82 & 82
\end{array}\right]
$$

After normalization, decision matrix $B$ is shown as follows:

$$
B=\left[\begin{array}{lllll}
0.25 & 0.00 & 1.00 & 0.50 & 0.20 \\
1.00 & 0.75 & 0.50 & 1.00 & 1.00 \\
0.50 & 0.25 & 0.25 & 0.00 & 0.40 \\
0.00 & 1.00 & 0.50 & 0.00 & 0.00 \\
0.75 & 0.50 & 0.00 & 0.50 & 0.40
\end{array}\right] .
$$

Step 6: obtain the ranking order of the alternatives and select the optimal project managers.

According to the Eqn (20), the normalized overall values of alternatives can be obtained:

$$
\begin{aligned}
& T\left(A_{i}\right)^{+}=\max \left\{T\left(A_{i}\right) \mid i=1,2, \ldots, 5\right\}=-0.50 ; \\
& T\left(A_{i}\right)^{-}=\min \left\{T\left(A_{i}\right) \mid i=1,2, \ldots, 5\right\}=-33.53 \\
& S\left(A_{1}\right)=\frac{T\left(A_{1}\right)-T\left(A_{i}\right)^{-}}{T\left(A_{i}\right)^{+}-T\left(A_{i}\right)^{-}}=0.23 ; \\
& S\left(A_{2}\right)=\frac{T\left(A_{2}\right)-T\left(A_{i}\right)^{-}}{T\left(A_{i}\right)^{+}-T\left(A_{i}\right)^{-}}=1.00 ; \\
& S\left(A_{3}\right)=\frac{T\left(A_{3}\right)-T\left(A_{i}\right)^{-}}{T\left(A_{i}\right)^{+}-T\left(A_{i}\right)^{-}}=0.00 ;
\end{aligned}
$$




$$
\begin{aligned}
& S\left(A_{4}\right)=\frac{T\left(A_{4}\right)-T\left(A_{i}\right)^{-}}{T\left(A_{i}\right)^{+}-T\left(A_{i}\right)^{-}}=0.15 ; \\
& S\left(A_{5}\right)=\frac{T\left(A_{5}\right)-T\left(A_{i}\right)^{-}}{T\left(A_{i}\right)^{+}-T\left(A_{i}\right)^{-}}=0.21 .
\end{aligned}
$$

The ranking order of the normalized overall values of alternatives $A_{i}$ can be determined:

$$
S\left(A_{2}\right)>S\left(A_{1}\right)>S\left(A_{5}\right)>S\left(A_{4}\right)>S\left(A_{3}\right) .
$$

Obviously, $A_{2}$ is the optimal project manager.

\subsection{Sensitivity analysis}

The purpose of sensitivity analysis is to determine the influence of decision maker's loss aversion preference on the decision making. In the decision making process above, the attenuation factor of the loss $\theta$, which represents the degree of the decision maker's loss-aversion, is taken as 1. Then the sensitivity is carried out varying the value of parameter $\theta$. The ranking order of alternatives with different value of $\theta$ is shown in Table 4 . It can be seen that the change of $\theta$ has no impact on the ranking order.

\subsection{Comparison and discussion}

To illustrate the effectiveness of the proposed extended TODIM method which combines $\lambda$-fuzzy measure with Choquet integral, the classical TODIM and TOPSIS method are used to make comparisons. TOPSIS method is one of the most popular methods to solve MCDM problem with the basic principle to choose the alternatives according to their distance from the ideal and negative-ideal solution. In the traditional TODIM method, the criteria are supposed to be independence with each other and the decision makers' loss averse preference is considered which is represented by the attenuation factor of the loss $\theta$. The comparison results are shown in Table 5.

As expressed in Table 5, all methods show that alternative $A_{2}$ is the best choice for project manager, indicating that the proposed extended TODIM method is effective and reliable. However, there still exist some ranking order differences among the proposed method and aforementioned two methods. The main reasons for the differences may be that the basic theories of these methods are different. Compared with the traditional TODIM method, both methods consider the bounded rational behavior of the decision makers. However, the interactive relationship between the criteria is not reflected in the traditional TODIM method and the incomplete criteria information is also not taken into account. TOPSIS method which choose alternative with the shortest distance from the positive ideal solution (best) and the farthest distance from negative-ideal solution (worst) (Hwang \& Yoon, 1981), is based on the concept of distance and is different from the proposed method. For the TOPSIS method, the relative closeness coefficient of each alternative is computed whereas the normalized overall value of each alternative is calculated for the proposed method. The superiorities of the proposed method can be summarized as follows: firstly, the bounded rational behaviors of the decision makers are taken into account. Secondly, the combinations of Choquet integral and $\lambda$-fuzzy measure are used to solve

Table 4. The ranking order of alternatives with different value of $\theta$

\begin{tabular}{|c|c|c|}
\hline Different value of $\theta$ & The normalized overall values of alternatives & Ranking order \\
\hline$\theta=1$ & $S\left(A_{1}\right)=0.23, S\left(A_{2}\right)=1, S\left(A_{3}\right)=0, S\left(A_{4}\right)=0.15, S\left(A_{5}\right)=0.21$ & $A_{2}>A_{1}>A_{5}>A_{4}>A_{3}$ \\
\hline$\theta=2$ & $S\left(A_{1}\right)=0.24, S\left(A_{2}\right)=1, S\left(A_{3}\right)=0, S\left(A_{4}\right)=0.12, S\left(A_{5}\right)=0.20$ & $A_{2}>A_{1}>A_{5}>A_{4}>A_{3}$ \\
\hline$\theta=3$ & $S\left(A_{1}\right)=0.24, S\left(A_{2}\right)=1, S\left(A_{3}\right)=0, S\left(A_{4}\right)=0.10, S\left(A_{5}\right)=0.19$ & $A_{2}>A_{1}>A_{5}>A_{4}>A_{3}$ \\
\hline$\theta=4$ & $S\left(A_{1}\right)=0.24, S\left(A_{2}\right)=1, S\left(A_{3}\right)=0, S\left(A_{4}\right)=0.08, S\left(A_{5}\right)=0.19$ & $A_{2}>A_{1}>A_{5}>A_{4}>A_{3}$ \\
\hline$\theta=5$ & $S\left(A_{1}\right)=0.24, S\left(A_{2}\right)=1, S\left(A_{3}\right)=0, S\left(A_{4}\right)=0.07, S\left(A_{5}\right)=0.18$ & $A_{2}>A_{1}>A_{5}>A_{4}>A_{3}$ \\
\hline
\end{tabular}

Table 5. The ranking order of alternatives with different methods

\begin{tabular}{|l|l|l|}
\hline & \multicolumn{1}{|c|}{ The normalized overall values of alternatives } & Ranking order \\
\hline Proposed method & $S\left(A_{1}\right)=0.23, S\left(A_{2}\right)=1, S\left(A_{3}\right)=0, S\left(A_{4}\right)=0.15, S\left(A_{5}\right)=0.21$ & $A_{2}>A_{1}>A_{5}>A_{4}>A_{3}$ \\
\hline Classical TODIM method & $S\left(A_{1}\right)=0.19, S\left(A_{2}\right)=1, S\left(A_{3}\right)=0.01, S\left(A_{4}\right)=0, S\left(A_{5}\right)=0.25$ & $A_{2}>A_{5}>A_{1}>A_{3}>A_{4}$ \\
\hline TOPSIS method & $k\left(A_{1}\right)=0.237, k\left(A_{2}\right)=0.559, k\left(A_{3}\right)=0.239, k\left(A_{4}\right)=0.286, k\left(A_{5}\right)=0.364$ & $A_{2}>A_{5}>A_{4}>A_{3}>A_{1}$ \\
\hline
\end{tabular}


the MCDM problem with the interactive criteria information. Thirdly, it can deal with the MCDM problem with incomplete information.

\section{Conclusions}

Project managers play very core roles in the infrastructure project management and selection of suitable project manager is very important for the success of the project. The decision makers' bounded rational behavior and the interactive relationship between criteria are not considered in the traditional evaluation methods of project manager's competency. Sometimes the evaluation information of criteria given by the decision makers is incomplete. In this paper an extended TODIM method based on $\lambda$-fuzzy measure and Choquet integral are suggested to evaluate the competency of the project managers. The proposed extend TODIM method is more efficient to deal with interactive and incomplete information about criteria given by the decision makers. Therefore, the presented method will provide some valuable references for the evaluation of project manager's competency.

\section{Acknowledgements}

The authors are highly grateful to the anonymous referees for their valuable comments and suggestions.

\section{Funding}

This work was supported by the National Key R\&D Program of China under Grant No. 2017YFB1400500; the National Natural Science Foundation of China under Grant No. 71802025 and Grant No. 71801017; Beijing Social Science Fund project under Grant No. 18JDGLB030; Program for Innovation Research in Central University of Finance and Economics.

\section{Author contributions}

Jielin YIN and Jian GUO conceived the study and were responsible for the design and development of the evaluation method. Tianmeng JI, Jingru CAI and Lei XIAO were responsible for the calculation of the numerical example. Jielin YIN wrote the Introduction section of the article. Jielin YIN and Jian GUO wrote the Literature review section of the article. Jian GUO wrote the Preliminary and Evaluation model section of the article. Tianmeng JI, Zhao DONG and Jian GUO wrote the Numerical Example section of the article.

\section{Disclosure statement}

Authors declare that they have not any competing financial, professional, or personal interests from other parties.

\section{References}

Cheng, M. I., Dainty, A. R., \& Moore, D. R. (2005). Towards a multidimensional competency-based managerial performance framework: A hybrid approach. Journal of Managerial Psychology, 20(5), 380-396.

https://doi.org/10.1108/02683940510602941

Choquet, G. (1953). Theory of capacities. Annales Institut Fourier, 5, 131-295. https://doi.org/10.5802/aif.53

CII-RT-281 (Construction Industry Institute-Research Team 281). (2012). Project management competency development: Tools, games, and exercises. Austin, Texas, USA.

Crawford, L., \& Arch, B. (1997). A global approach to project management competence. In Proceedings of the 1997 AIPM National Conference (pp. 220-228), AIPM. Sydney, Australia.

Edum-Fotwe, F. T., \& McCaffer, R. (2000). Developing project management competency: perspectives from the construction industry. International Journal of Project management, 18(2), 111-124. https://doi.org/10.1016/S0263-7863(98)90075-8

El-Sabaa, S. (2001). The skills and career path of an effective project manager. International Journal of Project Management, 19(1), 1-7. https://doi.org/10.1016/S0263-7863(99)00034-4

Fan, Z. P., Zhang, X., Chen, F. D., \& Liu, Y. (2013). Extended TODIM method for hybrid multiple criterion decision making problems. Knowledge-Based Systems, 42(2), 40-48. https://doi.org/10.1016/j.knosys.2012.12.014

Figueira, J., Greco, S., \& Ehrgott, M. (2005). Multiple criteria decision analysis: State of the art surveys. New York: Springer. https://doi.org/10.1007/b100605

Fisher, E. (2011). What practitioners consider to be the skills and behaviors of an effective people project manager. International Journal of Project Management, 29(8), 994-1002. https://doi.org/10.1016/j.ijproman.2010.09.002

Gaddis, P. O. (1959). The project manager. Harvard Business Review, 37(3), 89-97.

Gao, Z. Y., Zhu, L., Li, Z., \& Li, W. (2015). Threat evaluation of early warning detection based on incomplete criterion information TODIM method. In Proceedings of the $20153^{\text {rd }}$ International Conference on Machinery, Materials and Information Technology Applications (pp.40-47). Qingdao, Shandong, China. https://doi.org/10.2991/icmmita-15.2015.10

Gomes, L. F. A. M. (2009). An application of the TODIM method to the multi-criteria rental evaluation of residential properties. European Journal of Operational Research, 193(1), 204211. https://doi.org/10.1016/j.ejor.2007.10.046

Gomes, L. F. A. M., \& Lima, M. M. P. P. (1992a). TODIM: Basics and application to multicriteria ranking of projects with environmental impacts. Foundations of Computing and Decision Sciences, 16(1), 113-127.

Gomes, L. F. A. M., \& Lima, M. M. P. P. (1992b). From modeling individual preferences to multicriteria ranking of discrete alternatives: A look at prospect theory and the additive difference model. Foundations of Computing and Decision Sciences, 17(2), 171-184.

Gomes, L. F. A. M., Machado, M. A. S., \& Rangel, L. A. D. (2013a). Behavioral multi-criteria decision analysis: the TODIM method with criteria interactions. Annals of Operations Research, 211(1), 531-548. https://doi.org/10.1007/s10479-013-1454-9

Gomes, L. F. A. M., Machado, M. A. S., Costa, F. F. D., \& Rangel, L. A. D. (2013b). Criteria interactions in multiple criteria decision aiding: a Choquet formulation for the TODIM method. Procedia Computer Science, 17, 324-331. https://doi.org/10.1016/j.procs.2013.05.042 
Grabisch, M. (1997). Alternative representations of discrete fuzzy measure for decision making. International Journal of Uncertainty, Fuzziness and Knowledge Based Systems, 5, 587-607. https://doi.org/10.1142/S0218488597000440

Grabisch, M., Murofushi, T., \& Sugeno, M. (2000). Fuzzy measure and integrals. New York: Physica-Verlag.

Hanna, A. S. (2010). Construction labor productivity management and methods improvement. Hanna Consulting Group, Inc.

Hanna, A. S., Ibrahim, M. W., Lotfallah, W., Iskandar, K. A., \& Russell, J. S. (2016). Modeling project manager competency: an integrated mathematical approach. Journal of Construction Engineering and Management, 142(8), 129-145. https://doi.org/10.1061/(ASCE)CO.1943-7862.0001141

Hwang, C. L., \& Yoon, K. (1981). Multiple attribute decision making: Methods and applications. Berlin: Springer Verlag. https://doi.org/10.1007/978-3-642-48318-9

Ishii, K., \& Sugeno, M. (1985). A model human evaluation process using fuzzy measure. International Journal of Man-Machine Studies, 22(1), 19-38. https://doi.org/10.1016/s0020-7373(85)80075-4

Ji, P., Zhang, H. Y., \& Wang, J. Q. (2018). A fuzzy decision support model with sentiment analysis for items comparison in e-commerce: The case study of PConline.com. IEEE Transactions on Systems, Man, and Cybernetics: Systems, 48, 1-12. https://doi.org/10.1109/TSMC.2018.2875163

Jiang, Y. P., Liang, X., \& Zhang, Y. D. (2015). Method of TODIM decision making for incomplete evaluations. Operations Research and Management Science, 24(1), 116-121 (in Chinese).

Joshi, D., \& Kumar, S. (2016). Interval-valued intuitionistic hesitant fuzzy Choquet integral based TOPSIS method for multi-criteria group decision making. European Journal of Operational Research, 248(1), 183-191. https://doi.org/10.1016/j.ejor.2015.06.047

Kahneman, D., \& Tversky, A. (1979). Prospect theory: an analysis of decision under risk. Econometrica, 47(2), 263-291. https://doi.org/10.2307/1914185

Kohli, U., \& Chitkara, K. (2007). Project management handbook for engineers, construction professionals and business managers. New Delhi: Tata McGraw-Hill.

Kojadinovic, I. (2003). Modeling interaction phenomena using fuzzy measure: On the notions of interaction and independence. Fuzzy Sets and Systems, 135(3), 317-340. https://doi.org/10.1016/S0165-0114(02)00129-X

Krohling, R. A., Pacheco, A. G. C., \& Siviero, A. L. T. (2013). If-TODIM: an intuitionistic fuzzy TODIM to multi-criteria decision making. Knowledge-Based Systems, 53(9), 142-146. https://doi.org/10.1016/j.knosys.2013.08.028

Lourenzutti, R., Krohling, R. A., \& Reformat, M. Z. (2017). Choquet based TOPSIS and TODIM for dynamic and heterogeneous decision making with criteria interaction. Information Sciences, 408, 41-69. https://doi.org/10.1016/j.ins.2017.04.037

Maaleki, A., \& Cyrus, K. M. (2017). Project manager competency model based on ANP method in construction projects. In $7^{\text {th }}$ International Conference on Industrial Engineering and Operations Management (pp. 1281-1292). Rabat, Morocco.

Marichal, J. L. (2000). An axiomatic approach of the discrete Choquet integral as a tool to aggregate interacting criteria. IEEE Transactions on Fuzzy Systems, 8(6), 800-807. https://doi.org/10.1109/91.890347

Markus, L. H., Thomas, H. C., \& Allpress, K. N. (2005). Confounded by competencies? An evaluation of the evolution and use of competency models. New Zealand Journal of Psychology, 34(2), 117-126.

https://doi.org/10.1037/0894-4105.19.4.532
Meng, F. Y., Zhang, Q., \& Cheng, H. (2013). Approaches to multiple-criteria group decision making based on intervalvalued intuitionistic fuzzy Choquet integral with respect to the generalized $\lambda$-Shapley index. Knowledge-Based Systems, 37, 237-249. https://doi.org/10.1016/j.knosys.2012.08.007

Meredith, J. R., \& Mantel Jr., S. J. (2011). Project management: A managerial approach ( $8^{\text {th }}$ ed.). New York: John Wiley \& Sons. https://doi.org/10.1016/0263-7863(96)88306-2

Müller, R., \& Turner, J. R. (2007). Matching the project manager's leadership style to project type. International Journal of Project Management, 25(1), 21-32.

https://doi.org/10.1016/j.ijproman.2006.04.003

Murofushi, T., \& Sugeno, M. (1993). Some quantities represented by the Choquet integral. Fuzzy Sets and Systems, 56(2), 229235. https://doi.org/10.1016/0165-0114(93)90148-B

Nie, R. X., Tian, Z. P., Wang, J. Q., \& Hu, J. H. (2019). Pythagorean fuzzy multiple criteria decision analysis based on Shapley fuzzy measures and partitioned normalized weighted Bonferroni mean operator. International Journal of Intelligent Systems, 34(2), 297-324. https://doi.org/10.1002/int.22051

Ogunlana, S., Siddiqui, Z., Yisa, S., \& Olomolaiye, P. (2002). Factors and procedures used in matching project managers to construction projects in Bangkok. International Journal of Project Management, 20(5), 385-400.

https://doi.org/10.1016/S0263-7863(01)00017-5

Othman, N. L., \& Jaafar, M. (2013). Personal competency of selected women construction project managers in Malaysia. Journal of Engineering Design \& Technology, 11(3), 276-287. https://doi.org/10.1108/JEDT-02-2012-0005

Peng, J. J., Wang, J. Q., Hu, J. H., \& Tian, C. (2018). Multi-criteria decision-making approach based on single-valued neutrosophic hesitant fuzzy geometric weighted Choquet integral Heronian mean operator. Journal of Intelligent \& Fuzzy Systems, 35(3), 3661-3674. https://doi.org/10.3233/JIFS-18249

Russell, J. S., Jaselski, E. J., \& Lawrence, S. P. (1997). Continuous assessment of project performance. Journal of Construction Engineering and Management, 123(1), 64-71. https://doi.org/10.1061/(asce)0733-9364(1997)123:1(64)

Spencer, S., \& Spencer, L. M. (1993). Competence at work: models for superior performance. New York: John Wiley \& Sons. https://doi.org/10.2307/3666393

Sugeno, M. (1974). Theory of fuzzy integrals and its applications (Doctoral dissertation, Tokyo Institute of Technology).

Tan, C. Q. (2011). A multi-criteria interval-valued intuitionistic fuzzy group decision making with Choquet integral-based TOPSIS. Expert Systems with Applications, 38(4), 3023-3033. https://doi.org/10.1016/j.eswa.2010.08.092

Tan, C. Q., Jiang, Z. Z., \& Chen, X. H. (2015). An extended TODIM method for hesitant fuzzy interactive multi-criteria decision making based on generalized Choquet integral. Journal of Intelligent \& Fuzzy Systems, 29(1), 293-305. https://doi.org/10.3233/IFS-151595

Toney, F. (2001). The superior project manager: Global competency standards and best practices. CRC Press.

Toney, F., \& Powers, R. (1997). Best practices of project management groups in large functional organizations. Project Management Institute.

Turner, J. R. (1999). The handbook of project-based management: Improving the processes for achieving objectives. London: McGraw-Hill.

Wang, J. Q., Peng, J. J., Zhang, H. Y., \& Chen, X. H. (2019). Outranking approach for multi-criteria decision-making problems with hesitant interval-valued fuzzy sets. Soft Computing, 23(2), 419-430. https://doi.org/10.1007/s00500-017-2791-4 
Wang, X. K., Wang, J. Y. Q., \& Zhang, H. Y. (2018) Distancebased multi-criteria group decision-making approach with probabilistic linguistic term sets. Expert Systems, 36(2), 1-18. https://doi.org/10.1111/exsy.12352

Zavadskas, E. K., Turskis, Z., Tamosatiene, J., \& Marina, V. (2008). Multi-criteria selection of project managers by applying grey criteria. Technological and Economic Development of Economy, 14(4), 462-477.

https://doi.org/10.3846/1392-8619.2008.14.462-477

Zhang, X. L., \& Xu, Z. S. (2014). The TODIM analysis approach based on novel measured functions under hesitant fuzzy environment. Knowledge-Based Systems, 61(2), 48-58.

https://doi.org/10.1016/j.knosys.2014.02.006
Zhang, S. D. (2015). Research on the influence of project manager competence on performance in real estate enterprises. Journal of Engineering Management, 29(1), 154-158 (in Chinese).

Zhang, X., \& Fan, Z. P. (2011). A method for linguistic multiple criterion decision making based on TODIM. In Proceedings of the International Conference on Management and Service Science. Wuhan, Hubei, China.

https://doi.org/10.1109/ICMSS.2011.5999375 